\title{
Applying traditional passive concepts of resource efficiency and climate adaptation to improve the energy efficiency of modern buildings: a case study in Thessaloniki, Greece
}

\author{
S. Schelbach \\ HafenCity University Hamburg, Germany
}

\begin{abstract}
Learning from traditional architecture is accessing a wealth of experience which is revealed through the study of traditional buildings. In order to build resources efficiently and so the climate is adapted to a location, planners and architects could design energy efficient buildings based on this knowledge by an optimal adaptation to the site. This paper, as part of a $\mathrm{PhD}$ Thesis, shows a way to answer the question: What can we learn from traditional architecture and, most importantly, how can this knowledge be applied today?

As an exemplary examination, traditional houses in the upper city of Thessaloniki were investigated with the aim of identifying concepts of adaptation to the climatic conditions. The transferability of the results was tested through building simulations, using two apartment blocks as case studies. It could be shown that there is a potential to lower the energy demand in applying and involving traditional concepts to the refurbishment. Another result of the simulations was the strong interaction between different measures. Therefore it is important to compare different options of refurbishment strategies to understand their influence in energy efficiency and comfort.

This approach was developed as a method that provides a tool for planners and architects and could be applied to other locations and climatic conditions. The method can also be used for teaching purposes to introduce students to the variety of concepts and sensitize them to the built environment.

dieywords: climate adaptive architecture, resource efficiency, energy efficiency, traditional architecture, building simulation, adaptability.
\end{abstract}




\section{Introduction}

The study of traditional architecture has got a significant potential for finding concepts of passive measures to meet the demands for indoor comfort. As all European countries need to develop national plans to reduce $\mathrm{CO}_{2}$ emissions and improve energy efficiency, there is the need to find regional adapted concepts to meet these goals. Currently, residential building account for about $40 \%$ of the energy consumption in the European Union [1]. This leads to a high energy saving potential in lowering the energy demand of dwellings.

Within this survey traditional architecture in the Upper Town of Thessaloniki, Greece was studied as an exemplary examination to gain knowledge about the concepts used. This type of residential buildings developed over a long period within the Ottoman Empire and spread throughout the Balkan region [2, 3] with regional adaptations to local conditions. The examinations results showed effective concepts of climate adapted architecture concerning natural ventilation, the orientation of the buildings and their openings, shading devices and locally available building materials.

To investigate the transferability of these concepts to modern architecture two case studies were used.

\section{Concepts of climate adaptation of the examined traditional buildings}

The exemplary examination of the traditional buildings in the Upper Town of Thessaloniki was carried out by field studies, literature reviews, expert interviews and resident's surveys. Given the fact that the natural ventilation turned out to be particularly significant, measurements in a wind tunnel were performed. A reference building was developed to simulate indoor temperatures in summer and the heating demand, based on the collected data. The software used for the building simulations, PRIMERO Komfort 1.1 [4], is based on Energy Plus.

The buildings show a similar structure throughout the quarter and have ground floors made of massive natural stone masonry. Usually one, for some buildings two upper floors are built as a light structure of timber framework and brick masonry. The upper floors have got a finish with a clay-lime plaster and are painted in light colours while the ground floor often remains unplastered. Additionally to the roof overhang of about $60 \mathrm{~cm}$ the side hung windows have wooden shutters as shading devices. The hipped roofs are covered with red tiles. Being a locally adapted version of an Ottoman style house the houses usually have the typical representative room with an articulated eave, facing the street and allowing women a view into the public areas without being seen, as typical for these buildings from the Ottoman Period. The originally detached houses are today situated within a dense urban context on a slope facing the sea.

The passive concepts found through the examination by calculations, measurements and building simulations were divided into four topics. 


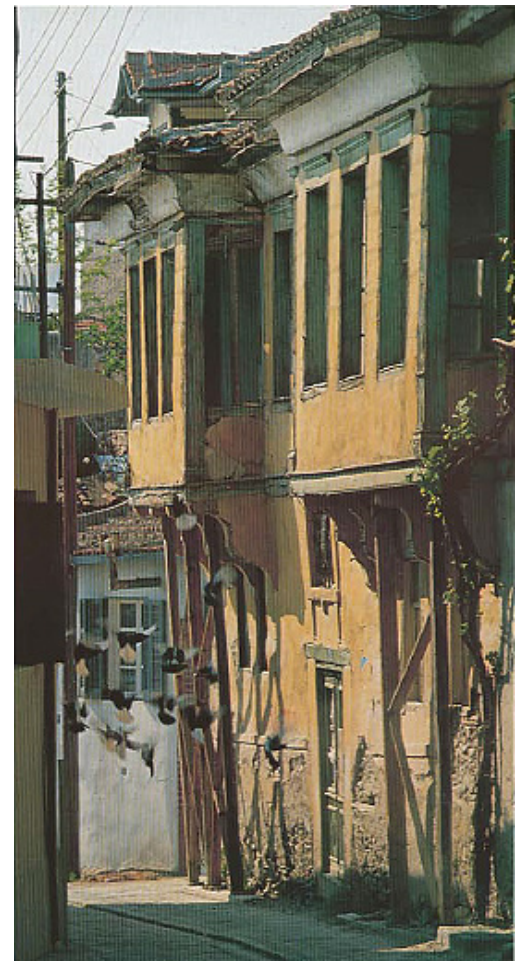

Figure 1: Typical building in the Upper Town of Thessaloniki for the exemplary examination.

\subsection{Natural ventilation}

The traditional buildings have a high potential for natural ventilation to avoid overheating in summer. The ventilation openings are the windows of the upper floor(s). As the upper floor was originally designed for the summer, the natural ventilation was investigated for this storey only. The ventilation is enabled through a high potential for cross ventilation due to the layout of the rooms and the orientation of the ventilation openings relative to the typical wind directions in summer. For the representative room the ventilation is enhanced through the additional windows at the sides of the eaves. These results were achieved by analysing data from experiments in a wind tunnel and building simulations with PRIMERO Komfort 1.1.

\subsection{Orientation with openings to the south}

The buildings orientation in the Upper Town is in an east-west direction if possible. This allows a long façade to the south with wide openings. The building simulations showed a potential for the reference building of twice as much solar gains in winter compared to a north-south orientation. On the other 
hand, the solar gains in summer are half as much respectively. This orientation also turned out to be the best alignment concerning the natural ventilation. Comparing different types of glazing the simulations showed no improvements of the heating demand for the reference building by using thermal insulation glazing due to lower solar gains compared to single glazing of the windows.

\subsection{Shading devices}

The wooden shutters with slats, painted in a light colour can efficiently be used as shading devices to avoid overheating in summer. However, the resident's surveys showed a lack of knowledge about making use of this. As the shutters allow shading without completely blocking the natural ventilation they have an advantage over widely used roller blinds. In winter the shutters can be used to improve the air tightness and insulation of the windows at night.

\subsection{Building materials}

For the buildings investigated, locally available materials such as natural stone, bricks, lime, clay and timber have been used. The techniques used were as efficient as possible but could be significantly improved by modern materials. It could be shown by the building simulations that an exterior insulation of the reference building would both decrease overheating in summer and the heating energy demand. The reference building, built with modern materials and exterior insulation showed the same results. The light colour of the facades of the traditional buildings has a positive effect against overheating in summer. This influence becomes unimportant as soon as the building has an exterior insulation preventing the structure from being heated up by the solar gain.

\section{Adaptability of passive measures to modern buildings}

In Thessaloniki, as in other cities in Greece, more than $50 \%$ of the building stock has been built between 1955 and 1980 [5, 6]. This time span counts for a period when the traditional techniques were not used any more but before energy efficiency of buildings was an important issue. A case study about the adaptability of the passive measures found by studying the traditional architecture was therefore made using two building from this period as case studies to investigate the potential in energy savings.

\subsection{Case study 1}

Building A is a typical six storey, mixed commercial and residential building built between 1955 and 1973, situated in the city centre of Thessaloniki. The load bearing structure is a concrete skeleton. The concrete frames are filled with brick masonry. There is no insulation on the facades and the roof. The windows of the building have timber frames and single glazing. The shading devices are exterior roller blinds and the balconies extending $1.25 \mathrm{~m}$ from the façade. 

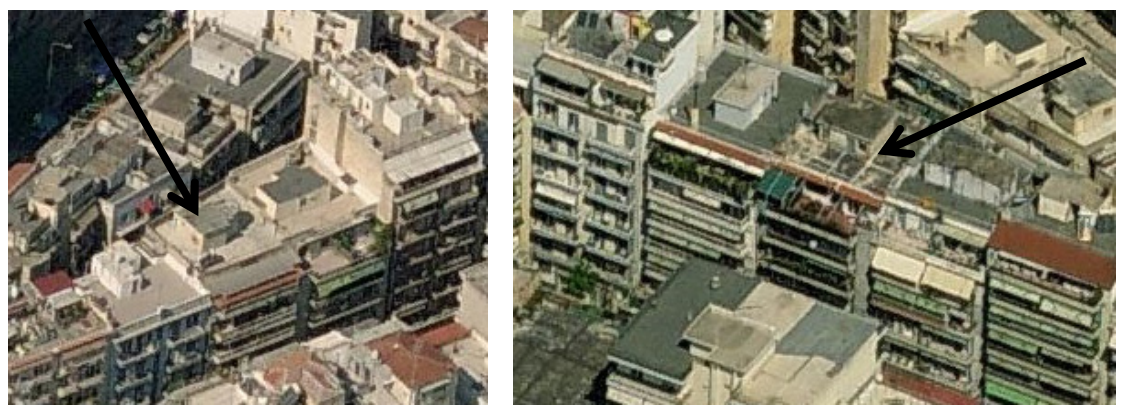

Figure 2: $\quad$ Case study, aerial views of Building A [7].

\subsection{Case study 2}

The residential Building B was built between 1973 and 1980 and is situated in a suburban district of Thessaloniki. Due to a regulation from 1973 it has an open ground floor with columns used as parking space. The floors 1-5 have three to four apartments; floor 6 is a setback storey with two apartments.

Building B is built as a concrete skeleton structure with brick masonry infill without an insulation of the external components like Building A. The aluminium frame windows have single glazing. Awnings underneath the balconies are used for shading of the transparent parts of the façade.
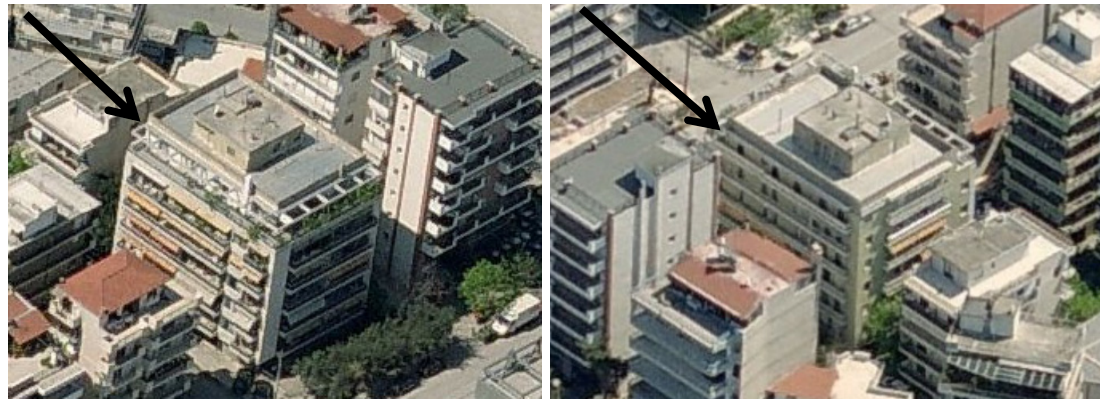

Figure 3: $\quad$ Case study, aerial views of Building B [7]

The application of passive concepts to the building was compared for different rooms of both buildings with the parameters of construction elements, glazing, ventilation, artificial lighting and shading devices as listed in table 1.

\section{Results of the case studies}

Building simulations were made for different combinations of passive measures to the sample building. The results, which are explained in the following 
Table 1: Parameter of the constructions used for the building simulation, insulation material with $\mathrm{U}=0.45 \mathrm{~W} / \mathrm{m} 2 \mathrm{~K}$.

\begin{tabular}{|c|c|c|}
\hline & $\begin{array}{l}\text { Used U-values of external } \\
\text { building components for } \\
\text { simulations in } \mathrm{W} / \mathrm{m}^{2} \mathrm{~K}\end{array}$ & $\begin{array}{l}\text { Minimum requirements of } \\
\text { currently valid regulation } \\
\text { KENAK }[8], \\
\text { U-value in } \mathrm{W} / \mathrm{m}^{2} \mathrm{~K}\end{array}$ \\
\hline roof/floor & $\begin{array}{l}0.39 \text { (insulation } 10 \mathrm{~cm} \text { ) } \\
0.16 \text { (insulation } 20 \mathrm{~cm} \text { ) }\end{array}$ & 0.4 \\
\hline walls & $\begin{array}{l}0.66 \text { (insulation } 5 \mathrm{~cm} \text { ) } \\
0.38 \text { (insulation } 10 \mathrm{~cm} \text { ) }\end{array}$ & 0.45 \\
\hline glazing & $\begin{array}{l}\text { thermal insulation glazing: } \\
\mathrm{g}=0.6, \mathrm{U}_{\mathrm{w}}=1.2 \mathrm{~W} / \mathrm{m}^{2} \mathrm{~K} \\
\text { sun protection glazing: } \\
\mathrm{g}=0.4, \mathrm{U}_{\mathrm{w}}=1.2 \mathrm{~W} / \mathrm{m}^{2} \mathrm{~K}\end{array}$ & 2.8 \\
\hline \multicolumn{3}{|c|}{ Other parameters (used values) } \\
\hline ventilation rate & $0.5 / \mathrm{h}$ & $\min .0 .5 / \mathrm{h}$ \\
\hline artificial lighting & $1501 \mathrm{~lx}$ & - \\
\hline shading devices & awnings/roller blinds & - \\
\hline
\end{tabular}

paragraph demonstrate that a transferability of these measures used in the traditional architecture to achieve thermal indoor comfort is possible. The outcome of the simulations is displays the effects of different measures to the heating energy demand in relation to the thermal comfort in summer. Based on the comfort model of DIN EN 15251 [9] an exceedance of indoor temperatures of $5 \%$ can be tolerated.

\subsection{Case study A}

For the investigation three rooms of building A were chosen and building simulations were made for several variations of applying the passive measures to understand interactions between different actions (Tab. 2).

For room A1 the simulation showed that wooden shutters as shading devices and an enhanced natural ventilation of $3 / \mathrm{h}$ leads to a sufficient heat protection in summer. Combined with an insulation of the external building components the heat protection is slightly better and the heating energy demand is reduced. Looking at the rooms A2 and A3 the results are different because of their position underneath the non-insulated roof. Without insulation the rooms become extremely warm in summer and have a high heating energy demand. Both rooms will have sufficient heat protection and a significant lower heating energy demand with insulation on walls and roof. Applying the minimum requirements 
Table 2: $\quad$ Combination of passive measures, investigated for Building A

\begin{tabular}{|l|l|}
\hline case & \\
\hline 0 & existing condition \\
\hline 1 & $0+$ wooden shutters as shading devices \\
\hline 2 & $1+$ natural ventilation $3 / \mathrm{h}$ and $\mathrm{n}_{50} 3 / \mathrm{h}$ \\
\hline 3 & $2+$ double size of windows \\
\hline 4 & $3+$ exterior insulation of $5 \mathrm{~cm}$ to all external building components \\
\hline $4 \mathrm{a}(\mathrm{A} 1)$ & 4 with thermal insulation glazing \\
\hline $4 \mathrm{~b}(\mathrm{~A} 1)$ & 4 with sun protection glazing \\
\hline 5 (A2/A3) & $\begin{array}{l}4+\text { exterior insulation of } 5 \mathrm{~cm} \text { to external walls, } \\
\text { exterior insulation of } 20 \mathrm{~cm} \text { to roof }\end{array}$ \\
\hline $5 \mathrm{a}$ & 5 with thermal insulation glazing \\
\hline $5 \mathrm{~b}$ & 5 with sun protection glazing \\
\hline 6 (A3) & $2+$ only roof with $20 \mathrm{~cm}$ exterior insulation \\
\hline 7 (A3) & $\begin{array}{l}6+\text { exterior insulation of } 10 \mathrm{~cm} \text { to external walls, } \\
\text { exterior insulation of } 20 \mathrm{~cm} \text { to roof }\end{array}$ \\
\hline 8 (A3) & $6+$ exterior insulation $: 10 \mathrm{~cm}$ to all external building components \\
\hline 9 & Minimum requirements of the currently valid regulation KENAK \\
\hline
\end{tabular}
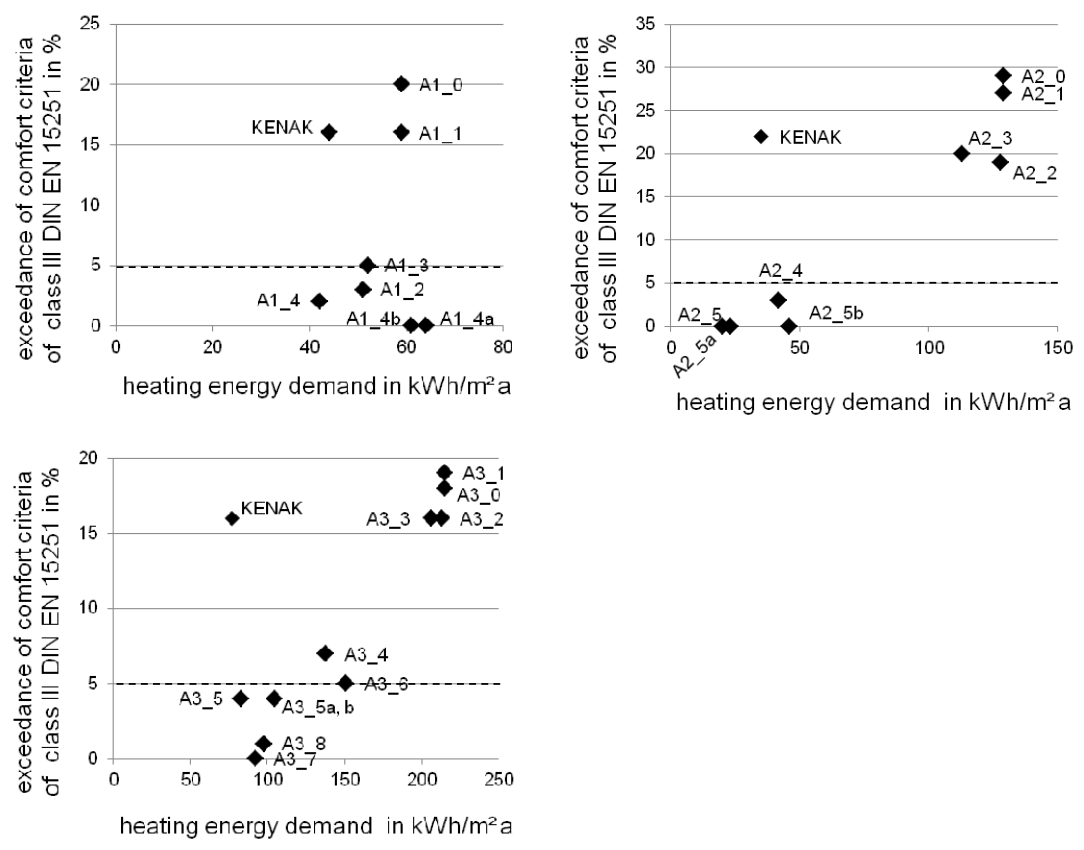

Figure 4: Rooms A1, A2, A3. Heat protection in summer and heating energy demand of the cases simulated. 
of the currently valid regulation KENAK shows that it meets sufficient measures to lower the heating energy demand, but missing requirements for natural ventilation and shading lead to overheating in summer.

\subsection{Case study B}

Four rooms were chosen for the simulations of the indoor room temperatures and the heating demand of these rooms, applying the passive measures (Tab. 3).

Table 3: $\quad$ Combination of passive measures, investigated for Building B.

\begin{tabular}{|l|l|}
\hline case & \\
\hline 0 & Existing condition \\
\hline 1 & $0+$ exterior insulation of 10 cm to all external building components \\
\hline 2 & $1+$ with wooden shutters as shading devices \\
\hline 3 & $2+$ natural ventilation $3 / \mathrm{h}$ and $\mathrm{n}_{50} 3 / \mathrm{h}$ \\
\hline $3 \mathrm{a}$ & 3 with thermal insulation glazing \\
\hline $3 \mathrm{~b}$ & 3 with sun protection glazing \\
\hline 4 & $3+$ double size of windows (B4 quadruple) \\
\hline 5 & $4+$ natural ventilation $4.5 / \mathrm{h}$ \\
\hline 6 & $\begin{array}{l}5+\text { exterior insulation of } 10 \mathrm{~cm} \text { to external walls, } \\
\text { exterior insulation of } 20 \mathrm{~cm} \text { to roof }\end{array}$ \\
\hline 7 & $\begin{array}{l}0+\text { natural ventilation } 3 / \mathrm{h} \text { und } \mathrm{n}_{50} 3 / \mathrm{h} \text { with wooden shutters as shading } \\
\text { devices }\end{array}$ \\
\hline 8 & $3+$ natural ventilation $7 / \mathrm{h}$ und $\mathrm{n}_{50} 3 / \mathrm{h}$ \\
\hline 9 & $0+$ natural ventilation $7 / \mathrm{h}$ und $\mathrm{n}_{50} 3 / \mathrm{h}$ \\
\hline 10 & Minimum requirements of the currently valid regulation KENAK \\
\hline
\end{tabular}

Rooms B1 and B2 in Case study B are situated on the first floor of the building the floor therefore being an external element. The simulation shows similar results for case 1 compared to the requirements of the KENAK. The difference between case 1 and the case "KENAK" is only glazing. Case 1 has single glazing, whereas the KENAK requires a glazing with an U-value of $2.8 \mathrm{~W} / \mathrm{m}^{2} \mathrm{~K}$. For case B3 and B4 in the top floor of the building the results are different. The single glazing leads to lower indoor temperatures in summer.

For B1 and B2 it could be shown that an exterior insulation and a shading of the windows with wooden shutters is sufficient to reduce the energy demand of the rooms by more than $50 \%$ as well as improve the heat protection in summer. For room B3 and B4 it could be shown that the internal temperatures in summer can be reduced by improving the natural ventilation (case 7 and 9), but the result is not satisfactory concerning the comfort and it does not improve the heating energy demand. For B3 these measures lead to a good result in combination with insulation of the external components. For room B4, a kitchen with a very small window, orientated to the east, a bigger window with an enhanced natural ventilation (B4_5) would be necessary to reach satisfactory results. 

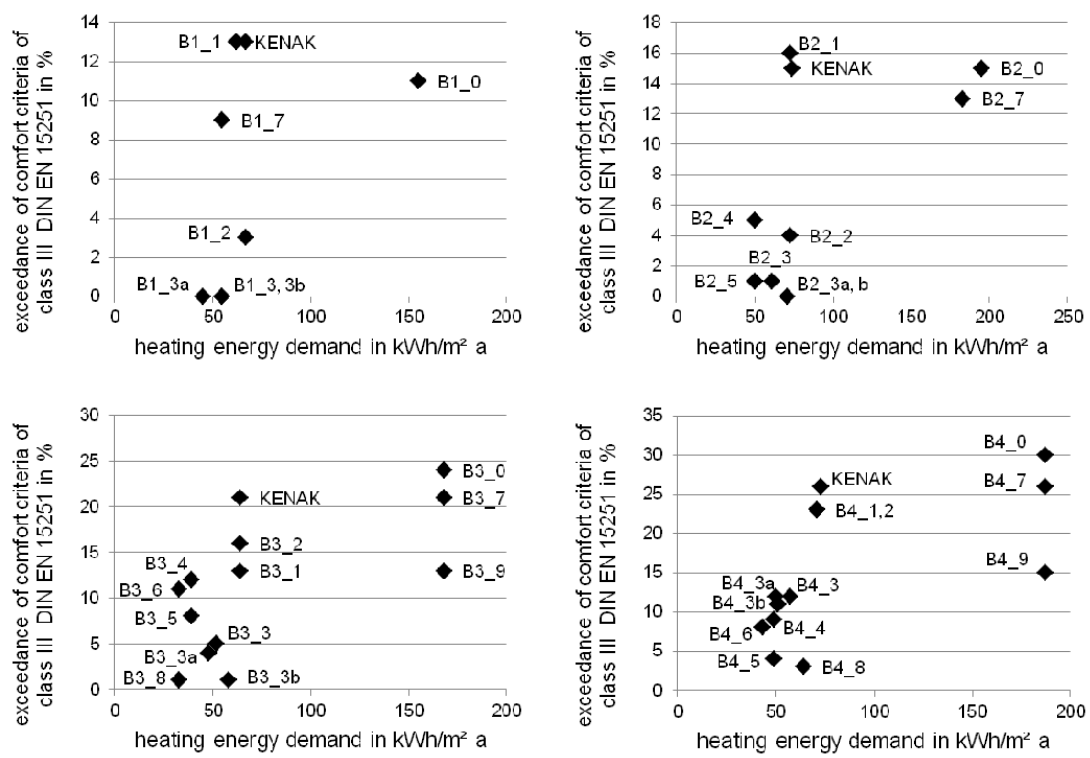

Figure 5: Rooms B1-B4. Heat protection in summer and heating energy demand of the cases simulated.

\subsection{Conclusion}

The results of the building simulation comparing different cases show that an improved natural ventilation in combination with an insulation of the external building components have a positive effect on both summer heat protection and the energy demand for heating. The effect of a thermal insulation glazing or a sun protection glazing is very small compared to the above measures. Concerning the requirements of the currently valid regulation the investigation demonstrates a lack of instructions to avoid overheating in summer.

The approach of the whole study was developed as a method to provide a tool for planners and architects. It was developed as a systematic approach for decision-making in 5 steps and tested within the context of the chosen example of traditional architecture in a city of the Mediterranean region. It could be applied to other locations and climatic conditions. Minor adaptation might be necessary for regions with extreme climate conditions.

Step A is a first site analysis to investigate, whether there is a traditional architecture and what are important aspects to check if this is a climate adapted and resource efficient construction method. Step B is the site analysis with a list of parameters to research by field studies, measurements, literature research, interviews or other methods in regard to the situation. Step C consists of an analysis of the data collected by using a building simulation software. In the next step (D) an evaluation shows if there are concepts which can be applied to 
modern buildings. In the last step (E) the application of the measures to a planning process and interactions with other actions is investigated.

The method can also be used for teaching purposes to introduce students to the variety of concepts that can be found by studying traditional architecture. It can be a tool to help them understand concepts of passive measures to meet the demands for indoor comfort and how to adapt these to modern buildings. Students could become aware of the built environment of a site and see how integrating the concepts being tested in the praxis over a long period of time can be a challenge.

\section{References}

[1] European Union 2014. Energy performance of buildings http://europa.eu/legislation_summaries/internal_market/single_market_for_g oods/construction/en0021 de.htm

[2] Anastasiadis, A. no date. Thessaloniki. Old Town. Athen: Melissa Publishing House. p. 16.

[3] Cerasi, M.; Bugatti, E.; D’Agostino, S. 2004. The Istanbul Divanyolu. A case study in Ottoman urbanity and architecture. p. 116. Würzburg: Ergon Verlag in Kommission.

[4] PRIMERO 1.1, Primero Komfort, HCU Hamburg, www.primerosoftware.de

[5] Theodoridou, I. 2012. Re-Polis $\backslash$ retrofitting Polykatoikia. The case of Mediterranean urban housing typology. Dissertation. Technische Universität Darmstadt.

[6] Balaras, Constantinos A. et al. 2007. European residential buildings and empirical assessment of the Hellenic building stock, energy consumption, emissions and potential energy savings. Building and Environment 42 (3), pp. 1298-1314.

[7] Kapou Public Limited Company of Geoinformatics, http://kapou.gr/

[8] Hellenic Republic 2010. Regulation of Energy Performance of Buildings (KENAK: Kanonismos energeiakis apodotikotitas ktiriwn). D6/B/5825 (in Greek).

[9] Deutsches Institut für Normung (2012): DIN EN 15251:2012-12. Eingangsparameter für das Raumklima zur Auslegung und Bewertung der Energieeffizienz von Gebäuden - Raumluftqualität, Temperatur, Licht und Akustik; Deutsche Fassung EN 15251:2007. Berlin: Beuth Verlag. 